\title{
Intake of phytic acid and myo-inositol lowers hepatic lipogenic gene expression and modulates gut microbiota in rats fed a high-sucrose diet
}

\author{
YUKAKO OKAZAKI $^{1}$, AYAKA SEKITA ${ }^{1}$ and TETSUYUKI KATAYAMA ${ }^{2}$ \\ ${ }^{1}$ Department of Human Life Studies, Faculty of Human Life Sciences, Fuji Women's University, Ishikari, \\ Hokkaido 061-3204; ${ }^{2}$ Institution of Life Sciences and Nutrition, Sapporo, Hokkaido 001-0037, Japan
}

Received September 6, 2017; Accepted March 6, 2018

DOI: $10.3892 /$ br.2018.1079

\begin{abstract}
Dietary phytic acid (PA) was recently reported by our group to suppress hepatic lipogenic gene expression and modulate gut microbiota in rats fed a high-sucrose (HSC) diet. The present study aimed to investigate whether the modulatory effects of PA depend on the dietary carbohydrate source and are attributed to the myo-inositol (MI) ring of PA. Male Sprague-Dawley rats were fed an HSC or a high-starch (HSR) diet with or without $1.02 \%$ sodium PA for 12 days. Subsequently, the rats were fed the HSC diet, the HSC diet containing $1.02 \%$ sodium PA or an HSC diet containing $0.2 \% \mathrm{MI}$ for 12 days. The HSC diet significantly increased the hepatic triglyceride (TG) concentration as well as the activity and expression of hepatic lipogenic enzymes compared with the HSR diet. The increases were generally suppressed by dietary PA with a concomitant increase in the fecal and cecal ratios of Lactobacillus spp. In rats fed the HSR diet, PA intake did not substantially affect the factors associated with hepatic lipid metabolism or gut microbiota composition. The effects of MI intake were similar to that of PA intake on hepatic lipogenesis and gut microbiota in rats fed the HSC diet. These results suggest that dietary PA downregulates hepatic lipogenic gene expression and modulates gut microbiota composition in rats fed an HSC diet but not in rats fed an HSR diet. The MI ring of PA may be responsible for the effects of PA intake on hepatic lipogenic gene expression and gut microbiota.
\end{abstract}

Correspondence to: Dr Yukako Okazaki, Department of Human Life Studies, Faculty of Human Life Sciences, Fuji Women's University, 4-5 Hanakawa Minami, Ishikari, Hokkaido 061-3204, Japan

E-mail: yokazaki@fujijoshi.ac.jp

Key words: phytic acid, myo-inositol, high-sucrose diet, fatty liver, hepatic lipogenic gene expression, gut microbiota, Lactobacillus spp.

\section{Introduction}

Phytic acid (PA) is a natural plant inositol hexaphosphate comprising up to $10-30 \mathrm{~g} / \mathrm{kg}$ dry matter in nuts, cereals, edible legumes and oil seeds $(1,2)$. The nutritional importance of PA in limiting the availability of essential dietary minerals has been emphasized $(1,2)$. Most of the reported actions of PA, including its effect on mineral absorption, have been linked to the chemical properties of the phosphate groups of its myo-inositol (MI) ring $(1,2)$. A recent study focused on the similarities between PA and MI in nutritional or physiological functions (3). The results suggested that PA and MI increase insulin sensitivity in adipocytes by increasing lipid storage capacity, improving glucose uptake and inhibiting lipolysis (3). Additionally, experiments on their anticancer effects by Vucenik and Shamsuddin (4) demonstrated that PA and MI prevented various types of cancer. To date, it has been demonstrated that equimolar concentrations of dietary PA and MI prevent sucrose- or xenobiotic-induced fatty liver by reducing hepatic lipogenic enzyme activity in rats (5-7). In addition, a practical level of dietary PA (approximately $0.035 \%$ ) has been reported to prevent fatty liver caused by a high-sucrose (HSC) diet in rats (8). However, in rats fed a high-starch (HSR) diet, dietary PA and MI did not affect hepatic triglyceride (TG) concentration or hepatic lipogenic enzyme activity (5-7).

It has been reported that digestion of PA in monogastric animals may be relatively inefficient and, like dietary fibers or oligosaccharides, undigested PA or partially digested inositol phosphates may reach the colon $(9,10)$. Vucenik and Shamsuddin (4) demonstrated that PA intake is effective in preventing colon carcinogenesis in rats and mice. Furthermore, dietary PA may modulate the composition of cecal organic acids, mucins and microbiota in rats fed a high-fat diet (11).

Studies have suggested that gut microbiota serve a role in the etiology of nonalcoholic fatty liver disease $(12,13)$. The preventive effect of PA on fatty liver caused by an HSC diet may be associated with the modulation of gut microbiota. In relation to this, a recent study by our group demonstrated that the preventive effect of dietary PA on fatty liver caused by an HSC diet was mediated by downregulation of the gene expression of hepatic lipogenic enzymes. In addition, PA intake was indicated to increase the fecal ratio of Lactobacillus spp. and 
depress the ratio of Clostridium coccoides (C. coccoides) in rats fed the HSC diet (14). However, the effect of PA intake on hepatic lipogenic gene expression and gut microbiota in rats fed an HSR diet remains unknown.

The present study aimed to evaluate whether the modulatory effects of PA intake on the gene expression of hepatic lipogenic enzymes and modulation of gut microbiota in rats fed an HSC diet depend on the dietary carbohydrate source and are attributed to the MI ring of PA. Cecal organic acids (OAs), which are products of bacterial fermentation, affect the levels of hepatic lipogenesis and cholesterogenesis $(15,16)$. Therefore, the effect of the dietary treatment on the cecal OA profile was also investigated.

\section{Materials and methods}

Animals and diets. A total of 42 male Sprague-Dawley rats (3-weeks-old, 54-67 g) were purchased from Japan SLC, Inc. (Hamamatsu, Japan). The animals were maintained according to the 'Guide for the Care and Use of Laboratory Animals' established by Fuji Women's University (Ishikari, Japan), and the study was approved by the university's ethics committee. The rats were individually housed in a room with a controlled temperature $\left(22-24^{\circ} \mathrm{C}\right)$, relative humidity (55-65\%) and under a 12-h light/dark cycle (light from 08:00 a.m. to 08:00 p.m.). Following ad libitum access to a non-purified commercial rodent powder diet (CE-2; CLEA Japan, Inc., Tokyo, Japan) for 3 days, the rats (78-90 g) were assigned to weight-matched groups ( $\mathrm{n}=6$ rats per group) and given ad libitum access to experimental diets and deionized water. Food intake and body weight were measured daily at 08:00 a.m. In experiment 1 , the rats from four groups were fed an HSR or HSC diet with or without $1.02 \%$ dodecasodium phytate (sodium PA; Sigma-Aldrich; Merck KGaA, Darmstadt, Germany) for 12 days. In experiment 2 , the rats from three groups were fed the HSC diet or HSC diets with $1.02 \%$ sodium PA or $0.2 \% \mathrm{MI}$ (Wako Pure Chemical Industries, Ltd., Osaka, Japan) for 12 days. Table I lists the compositions of the experimental diets (17). The molar concentration of the added MI was equivalent to that of the added PA. Feces were collected over the last 3 days of the experiments, stored at $-20^{\circ} \mathrm{C}$, and subsequently freeze-dried and milled. At the end of the feeding period, the rats were anesthetized with $3.0 \%$ isoflurane (Wako Pure Chemical Industries, Ltd.) and sacrificed to collect whole blood from the abdominal aorta. The serum was obtained by centrifugation at $2,000 \mathrm{x}$ g for $20 \mathrm{~min}$ at $4^{\circ} \mathrm{C}$ and then stored at $-80^{\circ} \mathrm{C}$. The liver and cecum were removed and weighed. A part of the liver was suspended in RNAlater stabilization reagent (Ambion; Thermo Fisher Scientific, Inc., Waltham, MA, USA) and stored at $-80^{\circ} \mathrm{C}$ until RNA extraction. The remaining portions of liver and cecum were immediately frozen using liquid nitrogen and stored at $-80^{\circ} \mathrm{C}$ until subsequent analyses.

Liver lipid and enzyme assays. Liver lipids were extracted using chloroform-methanol (2:1) solution as previously described (5-7). The solvent was removed by evaporation, and the total lipid (TL) was measured gravimetrically (5-7). The TG and cholesterol $(\mathrm{CH})$ concentrations were measured using enzymatic kits (total cholesterol C-Test Wako, cat.
Table I. Composition of basal diets.

\begin{tabular}{|c|c|c|}
\hline Component, \% (w/w) & High-starch & High-sucrose \\
\hline$\alpha$-corn starch & 64.95 & - \\
\hline Sucrose & - & 64.95 \\
\hline Casein & 20.00 & 20.00 \\
\hline Corn oil & 5.00 & 5.00 \\
\hline Cellulose & 5.00 & 5.00 \\
\hline Vitamin mixture $^{a}$ & 1.00 & 1.00 \\
\hline Mineral mixture ${ }^{b}$ & 3.50 & 3.50 \\
\hline L-cystine & 0.30 & 0.30 \\
\hline Choline bitartrate & 0.25 & 0.25 \\
\hline
\end{tabular}

${ }^{\mathrm{a}} \mathrm{AIN}-93$ vitamin mixture; ${ }^{\mathrm{b}} \mathrm{AIN}-93$ mineral mixture (17).

no. 439-17501 and triglyceride G-Test Wako, cat. no. 432-40201; Wako Pure Chemical Industries, Ltd.). The frozen liver was homogenized in nine volumes of $0.14 \mathrm{M} \mathrm{KCl}$ and centrifuged at $20,000 \mathrm{x}$ g for $30 \mathrm{~min}$ at $4^{\circ} \mathrm{C}$. The supernatant was used as the enzyme source. The activities of liver glucose-6-phosphate dehydrogenase (G6PD) and malic enzyme (ME) were determined spectrophotometrically by monitoring the formation of NADPH at $340 \mathrm{~nm}$, as previously described (5-7). The reaction mixtures were as follows: $0.017 \mathrm{M}$ glycylglycine, $3.5 \times 10^{-3} \mathrm{M}$ $\mathrm{MgSO}_{4}, 0.33 \times 10^{-3} \mathrm{M}$ NADP, $0.67 \times 10^{-3} \mathrm{M}$ glucose 6-phosphate for G6PD activity; and $0.017 \mathrm{M}$ glycylglycine, $7 \times 10^{-3} \mathrm{M}$ $\mathrm{MgSO}_{4}, 0.7 \times 10^{-3} \mathrm{M} \mathrm{MnSO}_{4}, 0.33 \times 10^{-3} \mathrm{M}$ NADP, $0.33 \times 10^{-3} \mathrm{M}$ malate for ME activity. All reagents were obtained from Wako Pure Chemical Industries, Ltd.

It has been recently demonstrated that dietary MI increases the plasma level of adiponectin in C57BL/6 mice fed a high-fat diet (18). Thus, the level of serum adiponectin was measured by using an enzyme-linked immunosorbent assay (cat. no. TI 25462309; Otsuka Pharmaceutical Co., Ltd., Tokushima, Japan) in experiment 2.

Reverse transcription-quantitative polymerase chain reaction $(R T-q P C R)$. mRNA expression levels were determined by RT-qPCR $(14,19)$. Total RNA was isolated using a NucleoSpin RNA kit (Takara Bio, Inc., Otsu, Japan) according to the manufacturer's instructions. Purified total RNA (400 ng) was converted to cDNA using a PrimeScript RT Master Mix (Takara Bio, Inc.). Real-time PCR was performed using SYBR Premix Ex Taq II (Takara Bio, Inc.), and samples were amplified in a LightCycler 480 Instrument (Roche Diagnostics $\mathrm{GmbH}$, Mannheim, Germany) under the following cycle conditions: $95^{\circ} \mathrm{C}$ for $30 \mathrm{sec}$ followed by 40 cycles of $95^{\circ} \mathrm{C}$ for $5 \mathrm{sec}$ and $60^{\circ} \mathrm{C}$ for $30 \mathrm{sec}$. The primer sets for $G 6 P D$ forward, GATGACATCCGCAAACAGAGTGA and reverse, GCTACA TAGGAGTTACGGGCAAAGA; $M E 1$ forward, CAGGCCTC CGTTAGCTTTGTTC and reverse, GCACAAGGACTGTAA ACAGCAGTGA; and fatty acid synthetase $(F A S)$ forward, GCTGCTACAAACAGGACCATCAC and reverse, TCTT GCTGGCCTCCACTGAC were purchased from Takara Bio, Inc. $(14,19)$. Melting curve analysis was performed following amplification to distinguish the targeted PCR product from the non-targeted PCR product using the LightCycler 480 Basic 
Table II. Body weight, food intake and lipid metabolic parameters in rats fed an HSR or HSC diet with or without PA (experiment 1).

\begin{tabular}{|c|c|c|c|c|c|c|c|c|}
\hline \multirow[b]{2}{*}{ Variables } & \multicolumn{2}{|c|}{ HSR } & \multicolumn{2}{|c|}{$\mathrm{HSR}+\mathrm{PA}$} & \multicolumn{2}{|c|}{ HSC } & \multicolumn{2}{|c|}{$\mathrm{HSC}+\mathrm{PA}$} \\
\hline & Mean & SEM & Mean & SEM & Mean & SEM & Mean & SEM \\
\hline Final body weight, $\mathrm{g}$ & 171 & 4 & 176 & 4 & 178 & 1 & 183 & 2 \\
\hline Food intake, $g / 12$ day & $174^{\mathrm{a}}$ & 4 & $177^{\mathrm{a}, \mathrm{b}}$ & 4 & $188^{\mathrm{b}, \mathrm{c}}$ & 2 & $193^{\mathrm{b}}$ & 3 \\
\hline \multicolumn{9}{|l|}{ Liver } \\
\hline Weight, g/100 g body wt. & $4.64^{\mathrm{a}}$ & 0.10 & $4.71^{\mathrm{a}}$ & 0.12 & $5.84^{\mathrm{b}}$ & 0.13 & $5.70^{\mathrm{b}}$ & 0.06 \\
\hline Total lipids, mg/g liver & $64.2^{\mathrm{a}}$ & 3.6 & $57.8^{\mathrm{a}}$ & 1.2 & $106.2^{\mathrm{b}}$ & 6.2 & $62.5^{\mathrm{a}}$ & 1.4 \\
\hline Triglyceride, $\mathrm{mg} / \mathrm{g}$ liver & $17.5^{\mathrm{b}}$ & 1.9 & $12.0^{\mathrm{a}}$ & 0.3 & $51.6^{c}$ & 5.6 & $23.2^{\mathrm{b}}$ & 1.6 \\
\hline Cholesterol, mg/g liver & 3.22 & 0.29 & 3.13 & 0.15 & 3.56 & 0.15 & 3.04 & 0.13 \\
\hline G6PD activity, $\mathrm{mU} / \mathrm{mg}$ protein & $34.1^{\mathrm{a}}$ & 5.4 & $36.7^{\mathrm{a}}$ & 1.7 & $69.1^{\mathrm{b}}$ & 7.8 & $53.1^{\mathrm{a}, \mathrm{b}}$ & 6.6 \\
\hline ME activity, $\mathrm{mU} / \mathrm{mg}$ protein & $28.9^{\mathrm{a}}$ & 2.9 & $32.1^{\mathrm{a}}$ & 2.8 & $50.6^{\mathrm{b}}$ & 5.6 & $35.7^{\mathrm{a}, \mathrm{b}}$ & 3.5 \\
\hline G6PD expression & $1.00^{\mathrm{a}}$ & 0.12 & $0.89^{\mathrm{a}}$ & 0.10 & $1.71^{\mathrm{b}}$ & 0.09 & $1.12^{\mathrm{a}}$ & 0.09 \\
\hline ME1 expression & $1.00^{\mathrm{a}, \mathrm{b}}$ & 0.06 & $0.72^{\mathrm{a}}$ & 0.05 & $2.08^{\mathrm{c}}$ & 0.07 & $1.09^{\mathrm{b}}$ & 0.06 \\
\hline FAS expression & $1.00^{\mathrm{a}}$ & 0.11 & $0.88^{\mathrm{a}}$ & 0.16 & $2.79^{\mathrm{b}}$ & 0.78 & $2.21^{\mathrm{a}, \mathrm{b}}$ & 0.06 \\
\hline
\end{tabular}

Mean values with their SEM; $n=6 .{ }^{\mathrm{a}-\mathrm{c}}$ Mean values with unlike superscript letters were significantly different, $\mathrm{P}<0.05$ (Tukey post hoc test for body weight, food intake, liver weight, hepatic cholesterol, hepatic ME activity, hepatic gene expression of lipogenic enzymes; Steel-Dwass test for liver total lipids, hepatic triglyceride and hepatic G6PD activity). HSR, high-starch; HSC, high-sucrose; PA, sodium phytate; G6PD, glucose-6-phosphate dehydrogenase; ME, malic enzyme; FAS, fatty acid synthetase; SEM, standard error of the mean.

Software v1.5. Relative expression levels were calculated for each sample following normalization to those of the reference gene GAPDH (forward, GGCACAGTCAAGGCTGAGAATG and reverse, ATGGTGGTGAAGACGCCAGTA), which was used as the endogenous control gene (19).

Microbiota analysis using $q P C R$. Fecal and cecal microbiota were analyzed as previously described (20). Briefly, bacterial genomic DNA was isolated from the freeze-dried and milled feces or the frozen cecal content using an UltraClean Fecal DNA extraction kit (MO BIO Laboratories; Qiagen, Inc., Valencia, CA, USA) according to the manufacturer's instructions. DNA was quantified using a Qubit dsDNA BR Assay kit (Thermo Fisher Scientific, Inc.). Bacterial groups were quantified by qPCR using the LightCycler 480 Instrument (Roche Diagnostics $\mathrm{GmbH}$ ) and the group-specific primers, which have been provided previously (20). Following initial denaturation at $95^{\circ} \mathrm{C}$ for $30 \mathrm{sec}, 40 \mathrm{PCR}$ cycles were performed with denaturation at $95^{\circ} \mathrm{C}$ for $5 \mathrm{sec}$, annealing at $55^{\circ} \mathrm{C}$ [total bacteria, Lactobacillus spp., Bifidobacterium spp., C. coccoides, C. Clostridium leptum (C. leptum) and Bacteroides] for $30 \mathrm{sec}$, and extension at $72^{\circ} \mathrm{C}$ for $15 \mathrm{sec}$ (total bacteria, Lactobacillus spp., Bifidobacterium spp. and Bacteroides) or $1 \mathrm{~min}$ (C. coccoides and C.leptum). Melting curve analysis was performed following amplification to distinguish the targeted PCR product from the non-targeted PCR product. Data were analyzed using the second derivative maximum method of the LightCycler 480 Basic Software v1.5. The amplification efficiencies (e) of real-time PCR for each primer set were estimated using a linear regression of the crossing point for each fecal DNA dilution versus the log dilution using the formula: $\mathrm{e}=\mathrm{x}-1$ /slope, where ' $\mathrm{x}$ ' was fold dilution. Efficiencies were between 1.94 and 1.99 (optimum value of 2.0). The relative abundance of microbial populations was expressed as the proportion of total bacterial 16S rRNA genes.

Cecal $\mathrm{pH}$ and OAs. The $\mathrm{pH}$ of cecal digesta was measured directly using a compact $\mathrm{pH}$ meter (B-212; Horiba, Ltd., Kyoto, Japan). The empty cecum was weighed and the weight of cecal digesta was calculated as the difference between the weight of the cecum and the weight of the empty cecum. Cecal OAs were measured by the internal standard method using high-performance liquid chromatography (HPLC; L-2130; Hitachi, Ltd., Tokyo, Japan) equipped with an Aminex HPX-87H ion exclusion column (7.8 mm i.d. x $30 \mathrm{~cm}$; Bio-Rad Laboratories, Inc., Hercules CA, USA) as previously described (20,21). Briefly, $500 \mathrm{mg}$ cecal digesta was homogenized in $5 \mathrm{ml}$ of $50 \mathrm{mmol} / \mathrm{l}$ $\mathrm{H}_{2} \mathrm{SO}_{4}$ containing $10 \mathrm{mmol} / \mathrm{l}$ 2,2-dimethyl butyric acid as an internal standard and subsequently centrifuged at $17,000 \mathrm{x} \mathrm{g}$ at $2^{\circ} \mathrm{C}$ for $20 \mathrm{~min}$. The supernatant was ultrafiltered, and the filtrate was examined by HPLC (column at $60^{\circ} \mathrm{C}$ ). The mobile phase $\left(5 \mathrm{mM} \mathrm{H}_{2} \mathrm{SO}_{4}\right)$ was delivered at a flow rate of $0.7 \mathrm{ml} / \mathrm{min}$. Cecal OAs were detected at $210 \mathrm{~nm}$ using a variable wavelength detector (L-2400; Hitachi, Ltd.).

Statistical analysis. All values were expressed as means \pm standard error of the mean. Normally distributed data were analyzed using two-way analysis of variance (ANOVA), whereas non-normally distributed data were analyzed using the non-parametric Kruskal-Wallis one-way ANOVA. The Tukey-Kramer post hoc test was performed when a significant effect was detected by two-way ANOVA. The Steel-Dwass post hoc test was conducted when a significant effect was detected by the Kruskal-Wallis one-way ANOVA. Associations between liver TGs and other parameters (liver lipogenic enzyme activity and gene expression, serum adiponectin, 
Table III. Fecal and cecal microbiota and cecal organic acids in rats fed an HSR or HSC diet with or without PA (experiment 1).

\begin{tabular}{|c|c|c|c|c|c|c|c|c|}
\hline \multirow[b]{2}{*}{ Variables } & \multicolumn{2}{|c|}{ HSR } & \multicolumn{2}{|c|}{$\mathrm{HSR}+\mathrm{PA}$} & \multicolumn{2}{|c|}{$\mathrm{HSC}$} & \multicolumn{2}{|c|}{$\mathrm{HSC}+\mathrm{PA}$} \\
\hline & Mean & SEM & Mean & SEM & Mean & SEM & Mean & SEM \\
\hline \multicolumn{9}{|l|}{ Feces } \\
\hline Weight, g/3 days & $3.89^{\mathrm{a}, \mathrm{b}}$ & 0.14 & $3.96^{\mathrm{a}, \mathrm{b}}$ & 0.13 & $3.54^{\mathrm{a}}$ & 0.07 & $4.11^{b}$ & 0.14 \\
\hline \multicolumn{9}{|l|}{ Microbiota, $\%$ of total bacteria } \\
\hline Lactobacillus spp. & $4.76^{\mathrm{a}, \mathrm{b}}$ & 1.81 & $7.20^{\mathrm{b}}$ & 2.11 & $0.15^{\mathrm{a}}$ & 0.03 & $9.29^{b}$ & 3.01 \\
\hline Bifidobacterium spp. & 0.077 & 0.044 & 0.153 & 0.090 & 0.013 & 0.009 & 0.006 & 0.001 \\
\hline Clostridium coccoides & $7.32^{\mathrm{a}}$ & 1.39 & $3.56^{\mathrm{b}}$ & 0.61 & $7.17^{\mathrm{b}}$ & 1.26 & $0.02^{\mathrm{a}}$ & 0.01 \\
\hline Bacteroides & $15.9^{\mathrm{a}, \mathrm{b}}$ & 2.1 & $14.7^{\mathrm{a}}$ & 2.9 & $17.1^{\mathrm{a}, \mathrm{b}}$ & 2.0 & $27.4^{\mathrm{b}}$ & 4.3 \\
\hline \multicolumn{9}{|l|}{ Cecum } \\
\hline $\begin{array}{l}\text { Tissue weight, } \mathrm{g} / 100 \mathrm{~g} \text { body wt. } \\
\text { Cecal digesta }\end{array}$ & $0.380^{\mathrm{b}}$ & 0.029 & $0.335^{\mathrm{a}, \mathrm{b}}$ & 0.011 & $0.264^{\mathrm{a}}$ & 0.017 & $0.322^{\mathrm{a}, \mathrm{b}}$ & 0.022 \\
\hline Weight, g & $2.47^{\mathrm{a}}$ & 0.12 & $3.22^{\mathrm{b}}$ & 0.19 & $1.93^{\mathrm{a}}$ & 0.12 & $2.25^{\mathrm{a}}$ & 0.11 \\
\hline $\mathrm{pH}$ & $6.90^{\mathrm{b}}$ & 0.18 & $6.22^{\mathrm{a}}$ & 0.05 & $7.62^{c}$ & 0.15 & $6.92^{b}$ & 0.09 \\
\hline \multicolumn{9}{|l|}{ Microbiota, $\%$ of total bacteria } \\
\hline Lactobacillus spp. & $1.66^{\mathrm{a}, \mathrm{b}}$ & 0.79 & $1.88^{\mathrm{b}}$ & 0.71 & $0.04^{\mathrm{a}}$ & 0.01 & $0.50^{\mathrm{b}}$ & 0.06 \\
\hline Bifidobacterium spp. & $0.0077^{\mathrm{a}, \mathrm{b}}$ & 0.0043 & $0.0277^{\mathrm{a}, \mathrm{b}}$ & 0.0083 & $0.0024^{\mathrm{a}}$ & 0.0003 & $0.0060^{\mathrm{b}}$ & 0.0015 \\
\hline Clostridium coccoides & $8.34^{\mathrm{b}}$ & 1.69 & $2.36^{\mathrm{a}, \mathrm{b}}$ & 0.78 & $5.39^{\mathrm{b}}$ & 0.79 & $0.48^{\mathrm{a}}$ & 0.36 \\
\hline Bacteroides & 30.2 & 1.8 & 45.7 & 8.8 & 30.3 & 2.0 & 53.4 & 13.9 \\
\hline \multicolumn{9}{|l|}{ Organic acids ( $\mu \mathrm{mol} /$ total digesta) } \\
\hline Succinate & $2.1^{\mathrm{a}}$ & 0.8 & $129.3^{\mathrm{b}}$ & 12.3 & $0.9^{\mathrm{a}}$ & 1.3 & $59.2^{\mathrm{b}}$ & 18.3 \\
\hline Lactate & 2.5 & 1.2 & 7.7 & 2.7 & 1.3 & 0.4 & 2.0 & 0.6 \\
\hline Acetate & $93.4^{\mathrm{a}, \mathrm{b}}$ & 12.4 & $129.9^{b}$ & 17.7 & $69.2^{\mathrm{a}}$ & 3.5 & $67.4^{\mathrm{a}, \mathrm{b}}$ & 6.6 \\
\hline Propionate & $34.6^{\mathrm{b}}$ & 3.5 & $39.4^{\mathrm{a}, \mathrm{b}}$ & 8.5 & $23.6^{\mathrm{a}, \mathrm{b}}$ & 1.5 & $18.0^{\mathrm{a}}$ & 1.7 \\
\hline n-Butyrate & 34.5 & 7.2 & 34.7 & 3.5 & 25.9 & 1.2 & 45.2 & 25.8 \\
\hline Total organic acids & $165.3^{\mathrm{a}, \mathrm{b}}$ & 24.2 & $341.2^{\mathrm{c}}$ & 23.3 & $121.2^{\mathrm{a}}$ & 4.9 & $190.7^{\mathrm{b}}$ & 25.3 \\
\hline
\end{tabular}

Mean values with their SEM; $n=6 .{ }^{\mathrm{a}-\mathrm{c}}$ Mean values with unlike superscript letters were significantly different, $\mathrm{P}<0.05$ (Tukey post hoc test for fecal weight, fecal Bacteroides, cecum weight, cecal digesta weight, cecal pH; Steel-Dwass test for fecal Lactobacillus spp., fecal Clostridium coccoides, fecal Bifidobacterium spp., cecal microbiota and cecal organic acids). HSR, high-starch; HSC, high-sucrose; PA, sodium phytate; SEM, standard error of the mean.

fecal and cecal microbiota and cecal OAs) were analyzed using the Spearman rank correlation analysis. Data analysis was performed using Excel Statistics 2012 for Windows (SSRI Co., Ltd., Tokyo, Japan). $\mathrm{P}<0.05$ was considered to indicate statistical significance.

\section{Results}

Dietary PA alleviates HSC diet-induced fatty liver pathology. In experiment 1 , body weight gain was not affected by supplementation of the dietary carbohydrate source with PA (Table II). Compared with the HSR diet, the HSC diet marginally increased food intake $(\mathrm{P}<0.05)$, whereas PA intake had no effect on food intake (Table II). The HSC diet induced significant increases in the liver weight, hepatic TL and TG concentrations, hepatic activities of G6PD and ME, and hepatic expression of G6PD, ME and FAS ( $\mathrm{P}<0.05$; Table II). The supplementation of PA in the diet effectively prevented the increases in hepatic TL and TG concentrations and significantly decreased the hepatic expression of G6PD and ME1 in rats fed the HSC diet $(\mathrm{P}<0.05)$. Similarly, $\mathrm{PA}$ intake decreased the hepatic activities of G6PD and ME, and the hepatic expression of FAS in rats fed the HSC diet, though these changes were determined as non-significant. In rats fed the HSR diet, PA intake did not alter these lipid metabolic parameters except for marginally decreasing the hepatic TG concentration $(\mathrm{P}<0.05)$.

PA intake, carbohydrate source, gut microbiota and cecal OAs. Dietary PA significantly increased fecal weight in rats fed the HSC diet $(\mathrm{P}<0.05$; Table III). The supplementation of PA in the HSC diet significantly increased the fecal ratio of Lactobacillus spp. and reduced the ratio of $C$. coccoides $(\mathrm{P}<0.05$; Table III). In rats fed the HSR diet, dietary PA did not have a significant effect on the fecal ratios of Lactobacillus spp. and $C$. coccoides. The fecal ratio of Bacteroides was higher in rats fed the HSC diet with PA compared with that in rats fed the HSR diet with PA $(\mathrm{P}<0.05)$. PA intake did not have a significant effect on the fecal ratios of Bifidobacterium spp. regardless of the dietary carbohydrate source (Table III).

The weight of cecal tissue was lower in rats fed the HSC diet compared with that in rats fed the HSR diet, and the weight of cecal digesta was significantly enhanced by PA intake in rats 
Table IV. Fecal and cecal microbiota and cecal organic acids in rats fed an HSC diet with or without MI or PA (experiment 2).

\begin{tabular}{|c|c|c|c|c|c|c|}
\hline \multirow[b]{2}{*}{ Variables } & \multicolumn{2}{|c|}{$\mathrm{HSC}$} & \multicolumn{2}{|c|}{$\mathrm{HSC}+\mathrm{PA}$} & \multicolumn{2}{|c|}{$\mathrm{HSC}+\mathrm{MI}$} \\
\hline & Mean & SEM & Mean & SEM & Mean & SEM \\
\hline Final body weight, g & 175 & 4 & 179 & 1 & 178 & 4 \\
\hline Food intake, g/12 days & 183 & 4 & 183 & 2 & 185 & 5 \\
\hline \multicolumn{7}{|l|}{ Liver } \\
\hline Weight, g/100g body wt. & $5.83^{\mathrm{a}}$ & 0.08 & $5.52^{\mathrm{a}, \mathrm{b}}$ & 0.08 & $5.31^{\mathrm{b}}$ & 0.12 \\
\hline \multicolumn{7}{|l|}{ Feces } \\
\hline Weight, $\mathrm{g} / 3$ days & 3.51 & 0.08 & 3.89 & 0.18 & 3.60 & 0.19 \\
\hline \multicolumn{7}{|l|}{ Cecum } \\
\hline Tissue weight, $\mathrm{g} / 100 \mathrm{~g}$ body wt. & 0.245 & 0.005 & 0.291 & 0.011 & 0.270 & 0.017 \\
\hline Cecal digesta weight, $\mathrm{g}$ & $1.73^{\mathrm{a}}$ & 0.05 & $2.08^{\mathrm{b}}$ & 0.09 & $1.85^{\mathrm{a}, \mathrm{b}}$ & 0.02 \\
\hline $\mathrm{pH}$ & $7.65^{\mathrm{c}}$ & 0.09 & $6.87^{\mathrm{a}}$ & 0.05 & $7.10^{\mathrm{b}}$ & 0.04 \\
\hline \multicolumn{7}{|l|}{ Microbiota, $\%$ of total bacteria } \\
\hline Lactobacillus spp. & $0.006^{\mathrm{a}}$ & 0.002 & $0.171^{\mathrm{b}}$ & 0.143 & $0.434^{\mathrm{b}}$ & 0.325 \\
\hline Bifidobacterium spp. & $0.0031^{\mathrm{a}}$ & 0.0005 & $0.0197^{\mathrm{b}}$ & 0.0098 & $0.0178^{\mathrm{a}, \mathrm{b}}$ & 0.0098 \\
\hline Clostridium coccoides & $4.54^{\mathrm{b}}$ & 0.50 & $1.02^{\mathrm{a}}$ & 0.51 & $4.30^{\mathrm{b}}$ & 0.36 \\
\hline Bacteroides & 31.9 & 1.5 & 52.6 & 11.3 & 26.4 & 1.9 \\
\hline \multicolumn{7}{|l|}{ Organic acids, $\mu \mathrm{mol} /$ total digesta } \\
\hline Succinate & $14.4^{\mathrm{a}}$ & 3.6 & $36.7^{\mathrm{b}}$ & 4.3 & $9.6^{\mathrm{a}}$ & 2.5 \\
\hline Lactate & 3.9 & 2.0 & 3.8 & 1.8 & 4.6 & 0.7 \\
\hline Acetate & 51.2 & 2.6 & 55.0 & 3.6 & 52.7 & 3.6 \\
\hline Propionate & 17.9 & 1.8 & 18.1 & 1.4 & 18.9 & 0.6 \\
\hline n-Butyrate & $18.8^{\mathrm{b}}$ & 1.2 & $21.2^{\mathrm{a}, \mathrm{b}}$ & 1.0 & $23.4^{\mathrm{a}}$ & 1.8 \\
\hline Total organic acids & $106.2^{\mathrm{a}}$ & 7.2 & $134.8^{b}$ & 4.8 & $109.2^{\mathrm{a}, \mathrm{b}}$ & 6.8 \\
\hline
\end{tabular}

Mean values with their SEM; $n=6 .{ }^{\mathrm{a}-\mathrm{c}}$ Mean values with unlike superscript letters were significantly different, $\mathrm{P}<0.05$ (Tukey post hoc test for body weight, food intake, liver weight, fecal weight, cecal pH, cecal Clostridium cocoides and cecal organic acids; Steel-Dwass test for cecum weight, cecal digesta weight, cecal Bifidobacterium spp., cecal Lactobacillus spp. and Bacteroides). HSR, high-starch; HSC, high-sucrose; PA, sodium phytate; MI, myo-inositol; SEM, standard error of the mean.

fed the HSR diet $(\mathrm{P}<0.05$; Table III). The cecal $\mathrm{pH}$ was higher in rats fed the HSC diet compared with that in rats fed the HSR diet. PA intake significantly lowered the cecal $\mathrm{pH}$ regardless of the dietary carbohydrate source $(\mathrm{P}<0.05$; Table III). In rats fed the HSC diet, dietary PA significantly increased not only the fecal ratio but also the cecal ratio of Lactobacillus spp. and significantly decreased the cecal ratio of $C$. coccoides $(\mathrm{P}<0.05$; Table III). In addition, in rats fed the HSC diet, dietary PA significantly increased the cecal ratio of Bifidobacterium spp. $(\mathrm{P}<0.05)$. In rats fed the HSR diet, dietary PA had no significant effect on the cecal microbiota composition (Table III).

In rats fed the HSR diet or the HSC diet, the cecal succinate level was markedly enhanced by PA intake $(\mathrm{P}<0.05$; Table III). The cecal acetate level was significantly higher in rats fed the HSR diet with PA compared with that in rats fed the HSC diet without PA. Furthermore, the cecal propionate level was significantly higher in rats fed the HSR diet without PA compared with that in rats fed the HSC diet with $\mathrm{PA}(\mathrm{P}<0.05$; Table III).

Similar effects of PA and MI intake on HSC-induced fatty liver pathology. In rats fed the HSC diet (experiment 2), dietary
PA and MI did not affect body weight gain or food intake (Table IV). Liver weight was significantly reduced by MI intake $(\mathrm{P}<0.05)$, and moderately by PA intake (Table IV), and $\mathrm{PA}$ or MI intake decreased the liver TL and TG concentrations $(\mathrm{P}<0.05$; Fig. 1A). The activity of hepatic ME was significantly decreased by dietary PA intake $(\mathrm{P}<0.05)$, and moderately by MI intake (Fig. 1B). Although the activity and expression of hepatic G6PD were not significantly affected by dietary PA or $\mathrm{MI}$, the expression of hepatic $M E 1$ and $F A S$ in rats fed the HSC diet with PA or MI was decreased $(\mathrm{P}<0.05$; Fig. $1 \mathrm{~B}$ and $\mathrm{C})$. The serum adiponectin level was significantly increased by dietary MI $(\mathrm{P}<0.05)$, whereas it was moderately increased by PA in rats fed the HSC diet (Fig. 2).

Comparative effect of $P A$ and MI on gut microbiota and cecal $O A$. In experiment 2 , the fecal and cecal weights were not significantly affected by dietary PA or MI (Table IV). In accordance with experiment 1 , PA intake significantly increased the weight and lowered the $\mathrm{pH}$ of the cecal digesta $(\mathrm{P}<0.05)$. Similarly, MI intake moderately increased the digesta weight and significantly decreased the digesta $\mathrm{pH}$ (Table IV). The supplementation of PA in the HSC diet significantly increased 
Table V. Associations between liver TG concentration and lipid metabolic parameters, gut microbiota and cecal OAs.

Correlation coefficient, $r$

Liver TG (mg/g tissue)

Parameters

Experiment 1 Experiment 2

Liver

G6PD activity, $\mathrm{mU} / \mathrm{mg}$ protein

$\begin{array}{ll}0.763^{\mathrm{b}} & 0.769^{\mathrm{b}} \\ 0.805^{\mathrm{b}} & 0.747^{\mathrm{b}} \\ 0.741^{\mathrm{b}} & 0.516^{\mathrm{a}} \\ 0.876^{\mathrm{b}} & 0.706^{\mathrm{b}} \\ 0.718^{\mathrm{b}} & 0.693^{\mathrm{b}}\end{array}$

G6PD expression

ME expression

FAS expression

$-0.559^{a}$

Adiponectin, $\mu \mathrm{mol} / \mathrm{dl}$

ND

$-0.562^{\mathrm{a}}$

Feces microbiota, \%

Lactobacillus spp.

$-0.569^{b}$

$-0.317$

Bifidobacterium spp.

$-0.672^{b}$

$0.793^{\mathrm{b}}$

Clostridium coccoides

0.230

0.249

Cecum microbiota, \%

$\begin{array}{lcc}\text { Lactobacillus spp. } & -0.702^{\mathrm{b}} & -0.739^{\mathrm{b}} \\ \text { Bifidobacterium spp. } & -0.597^{\mathrm{b}} & -0.821^{\mathrm{b}} \\ \text { Clostridium coccoides } & 0.212 & -0.508^{\mathrm{a}} \\ \text { Bacteroides } & -0.275 & 0.285 \\ \text { Cecum OAs, } \mu \mathrm{mol} / \text { total digesta } & & \\ \text { Succinate } & -0.541^{\mathrm{b}} & -0.099 \\ \text { Lactate } & -0.577^{\mathrm{b}} & -0.100 \\ \text { Acetate } & -0.490^{\mathrm{a}} & 0.044 \\ \text { Propionate } & -0.506^{\mathrm{a}} & -0.100 \\ \text { n-Butyrate } & -0.376 & -0.103\end{array}$

There was significant correlation between parameters, ${ }^{\mathrm{a}} \mathrm{P}<0.05$ and ${ }^{\mathrm{b}} \mathrm{P}<0.01$. ND, not determined; G6PD, glucose-6-phosphate dehydrogenase; ME, malic enzyme; FAS, fatty acid synthetase; TG, triglyceride; OA, organic acid.

the fecal ratio of Lactobacillus spp. and decreased the fecal ratio of $C$. coccoides compared with the HSC diet alone $(\mathrm{P}<0.05$; Fig. 3). Similar to PA intake, MI intake decreased the ratio of $C$. coccoides $(\mathrm{P}<0.05)$ and moderately increased the ratio of Lactobacillus spp. (Fig. 3). No significant differences were detected in the fecal ratio of Bifidobacterium spp. among the three groups (Fig. 3). As presented in Table IV, dietary PA or MI significantly increased the cecal ratio of Lactobacillus spp. The cecal ratio of $C$. coccoides was decreased by dietary PA $(\mathrm{P}<0.05)$, but was not affected by dietary MI (Table IV). Dietary PA significantly increased the cecal ratio of Bifidobacterium spp. ( $\mathrm{P}<0.05$; Table IV); dietary MI also increased the ratio, but its effect was not significant (Table IV). Dietary PA or MI did not affect the cecal ratio of Bacteroides (Table IV). The cecal succinate level was increased by the supplementation of PA in the HSC diet, as in experiment 1; whereas it was unaffected by MI intake. MI intake also marginally increased the cecal butyrate level
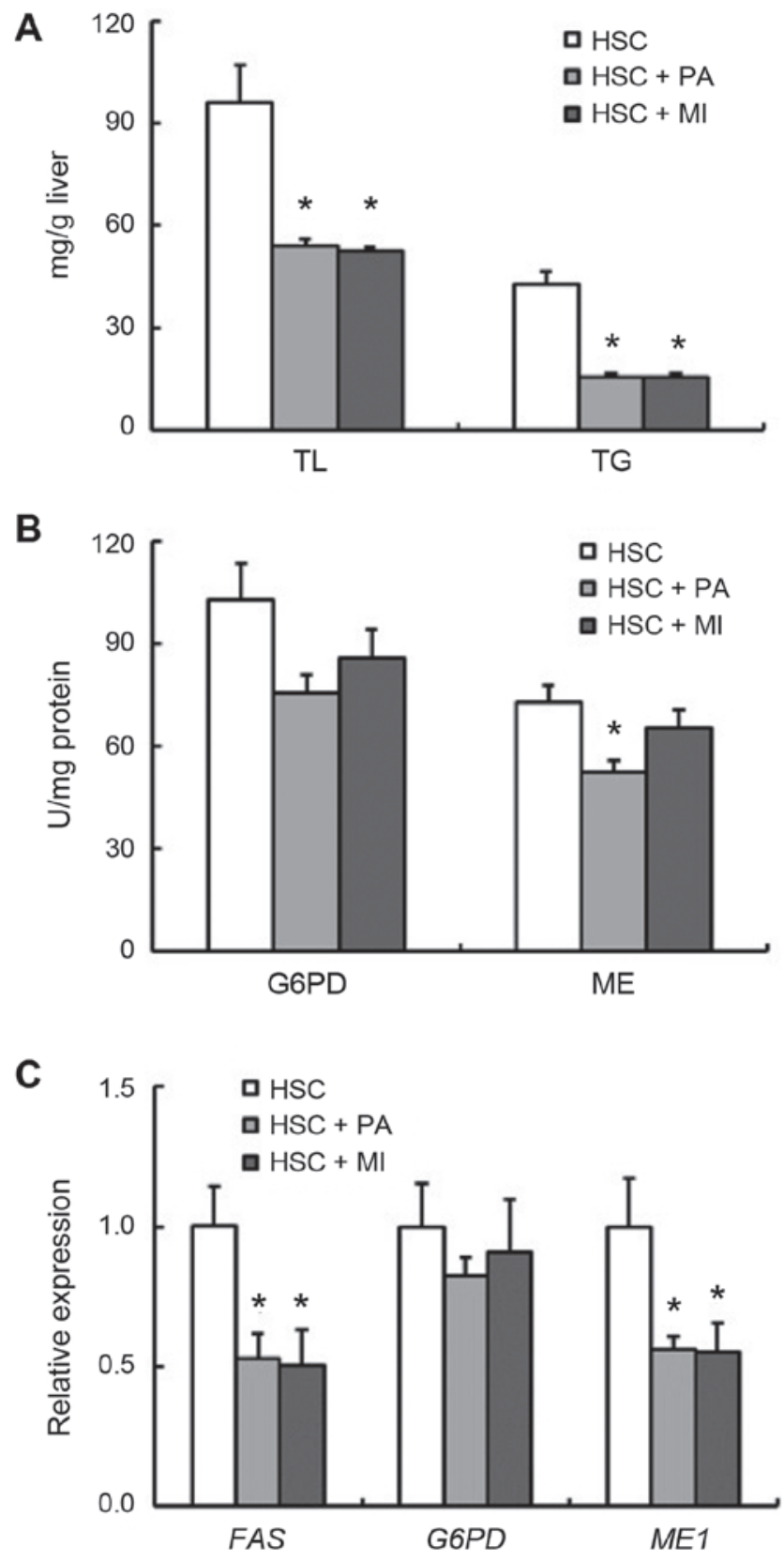

Figure 1. Hepatic lipid content and the activities and expression of hepatic lipogenic enzymes in rats fed a HSC diet with or without $1.02 \%$ PA or $0.2 \% \mathrm{MI}$. (A) Hepatic TL and TG concentrations. (B) Activities of hepatic G6PD and ME. (C) Expression of hepatic FAS, G6PD and ME1. Each bar represents the mean \pm standard error of the mean values $(n=6)$. ${ }^{*} \mathrm{P}<0.05$ vs. HSC group. HSC, high-sucrose; PA, sodium phytate; MI, myo-inositol; TL, total lipids; TG, triglyceride; G6PD glucose-6-phosphate dehydrogenase; ME, malic enzyme; FAS, fatty acid synthetase.

$(\mathrm{P}<0.05)$. The levels of all other cecal OAs were unaffected by PA or MI intake.

Relation between liver TG and other parameters. The data from all rats were used for correlation analysis. As depicted in Table V, the liver TG concentration was positively correlated with the activity and expression of hepatic lipogenic enzymes in experiments 1 and 2, and negatively correlated with the serum adiponectin level in experiment $2(\mathrm{P}<0.05)$. Fecal and cecal Lactobacillus spp. correlated negatively with the liver TG concentration in experiments 1 and $2(\mathrm{P}<0.05)$. 


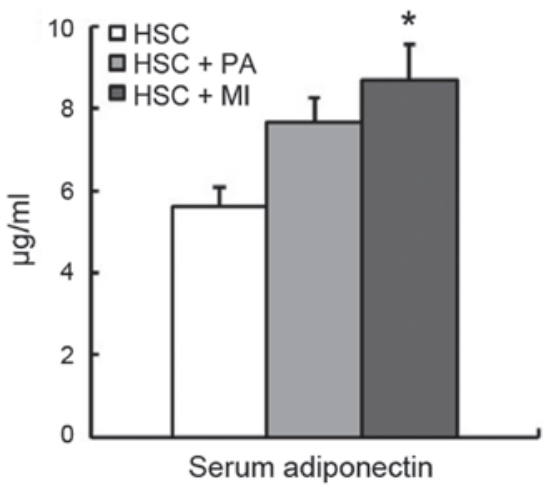

Figure 2. Serum adiponectin in rats fed an HSC diet with or without $1.02 \%$ sodium PA or $0.2 \%$ MI. Each bar represents mean \pm standard error of the mean values $(n=6) .{ }^{*} \mathrm{P}<0.05$ vs. HSC group. HSC, high-sucrose; PA, sodium phytate; MI, myo-inositol.

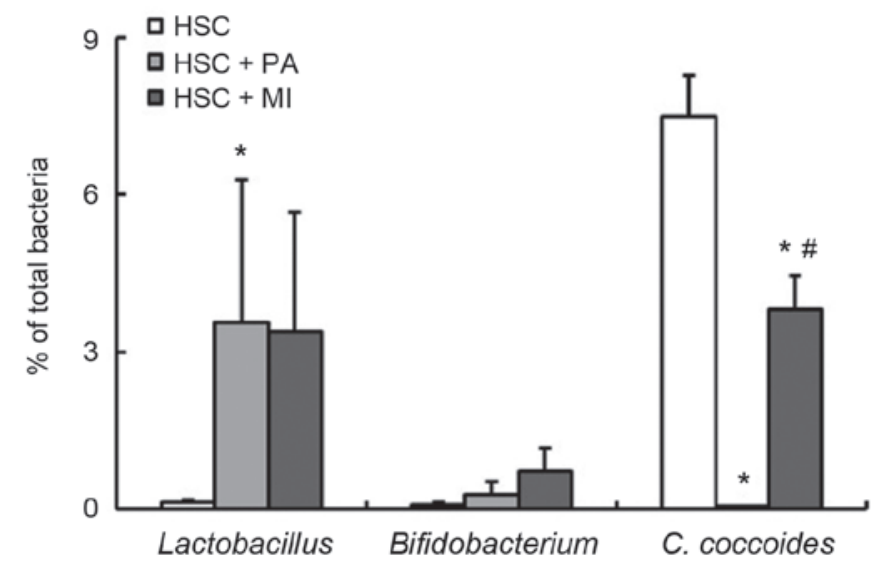

Figure 3. Fecal microbiota in rats fed an HSC diet with or without $1.02 \%$ sodium PA or $0.2 \%$ MI. Each bar represents the mean \pm standard error of the mean values $(\mathrm{n}=6) .{ }^{*} \mathrm{P}<0.05$ vs. HSC group; ${ }^{*} \mathrm{P}<0.05$ vs. HSC + PA group. HSC, high-sucrose; PA, sodium phytate; MI, myo-inositol; C. cocoides, Clostridium cocoides.

A similar association was observed between the abundance of Bifidobacterium spp. and liver TG concentration, although this correlation was not significant for fecal abundance in experiment 2 . The liver TG concentration exhibited a significant positive correlation with the fecal and cecal abundance of C. coccoides in experiment $2(\mathrm{P}<0.05)$; while this correlation was not significant in experiment 1 . The cecal levels of succinate, lactate, acetate and propionate exhibited a significant negative correlation with the liver TG concentration in experiment $1(\mathrm{P}<0.05)$ : while this correlation was not significant in experiment 2 (Table $\mathrm{V}$ ).

\section{Discussion}

The present study demonstrated that the effect of dietary MI was similar to that of dietary PA on the expression of hepatic lipogenic enzymes and gut microbiota in rats fed an HSC diet. Sakamoto et al (22) reported that $\left[{ }^{3} \mathrm{H}\right] \mathrm{PA}$ is absorbed and distributed to various organs MI and MI-monophosphate in rats. They speculated that soluble PA when administered in drinking water is rapidly absorbed through the stomach and upper small intestine, becomes quickly dephosphorylated within the mucosal cells and is distributed to various organs as inositol and MI-monophosphate (22). In a previous study, dietary PA significantly increased the hepatic level of free MI in rats (7). It is postulated that the MI ring of PA may be responsible for the effects of PA on hepatic lipid metabolism and gut microbiota in rats fed an HSC diet. The present results suggest that MI, a vitamin-like substance contained in various foods including milk and citrus fruits $(23,24)$, may be a modulating factor of gut microbiota in rats fed an HSC diet.

In accordance with previous results $(5,7,14)$, the current study demonstrated that dietary PA may prevent fatty liver pathology, which may at least in part occur via a reduction in the activity and expression of hepatic lipogenic enzymes. Furthermore, in rats fed the HSC diet, dietary PA increased the ratio of Lactobacillus spp. and decreased the ratio of C. coccoides in the cecum and feces. The current data also confirm our previous findings $(5,6)$ that PA intake does not affect the hepatic TG concentration and the activity of hepatic lipogenic enzymes in rats fed the HSR diet. The present study indicated that dietary PA did not significantly affect the expression of hepatic lipogenic enzymes and gut microbiota in rats fed the HSR diet. Thus, taken together with previous reports $(5,7,14)$, our findings may suggest that dietary PA normalizes hepatic TG concentration as well as the activity and expression of hepatic lipogenic enzymes with a concomitant modulation of gut microbiota in rats fed a lipogenic diet.

The gut microbiota including Lactobacillus spp. and Clostridium spp. are established to regulate hepatic lipogenesis and fat storage $(12,13)$. In the present study, the hepatic TG concentration was positively correlated with the activity and expression of hepatic lipogenic enzymes and negatively correlated with the fecal and cecal ratios of Lactobacillus spp. $\mathrm{Xu}$ et al (25) reported that the hepatic TL concentration was negatively correlated with the concentration of gut Lactobacillus spp. in a nonalcoholic fatty liver rat model. Ritze et al (26) demonstrated that Lactobacillus rhamnosus protected against fatty liver disease induced by a high-fructose diet in mice. Collectively, these findings indicate that hepatic TL and TG concentrations are associated with gut microbiota, particularly with the abundance of Lactobacillus spp. Thus, dietary PA or MI may ameliorate fatty liver pathology by modifying the abundance of Lactobacillus spp. in the gut of rats fed an HSC diet.

It is well known that the plasma level of adiponectin is decreased in patients with nonalcoholic fatty liver disease $(27,28)$. The delivery of recombinant adiponectin has been reported to alleviate alcoholic and nonalcoholic fatty liver diseases in mice (29). The present study observed that dietary MI increased the serum level of adiponectin. The same trend was observed in rats fed the HSC diet with PA. The serum adiponectin level was also negatively correlated with the liver TG concentration. Croze et al (18) recently demonstrated that dietary MI increased the plasma level of adiponectin in C57BL/6 mice fed a high-fat diet. The effect of dietary MI and PA on the serum level of adiponectin may be associated with their anti-fatty liver effect in rats fed an HSC diet. At present, a cDNA microarray analysis is in progress by our group to determine the gene expression profile in the liver of rats fed an HSC diet in response to dietary PA and MI. 
Liver transcriptome analysis has already revealed that PA or MI intake suppressed the expression of genes associated with lipid, fatty acid and long-chain fatty-acyl-CoA biosynthesis processes and the NADP-binding domain, which were upregulated by the HSC diet (unpublished data).

Cecal OAs, which are products of bacterial fermentation, affect hepatic lipogenesis and cholesterogenesis in rats $(15,16)$. In the present study, dietary PA increased the cecal succinate level in rats regardless of the dietary carbohydrate source. However, dietary MI did not affect the cecal succinate level in rats fed the HSC diet, and the liver TG concentration did not correlate with the cecal succinate level in experiment 2. Thus, it may be speculated that the levels of cecal OAs are not linked to the anti-fatty liver effect of PA and MI in rats fed an HSC diet. It has previously been demonstrated that dietary PA increased the cecal butyrate level in rats fed a high-fat diet (11). Dietary PA may affect the levels of cecal OAs differently according to the dietary composition. Further studies are necessary to investigate the association between the effect of dietary PA on the levels of cecal OAs with varying dietary composition in rats.

In conclusion, the present study indicated that dietary PA prevents fatty liver pathology by reducing the activity and expression of hepatic lipogenic enzymes. In addition, it may modulate the gut microbiota in rats fed an HSC diet, while having no effect on hepatic lipid metabolism or gut microbiota in rats fed an HSR diet. Therefore, it may be suggested that in rats fed a high-lipogenic diet, dietary PA normalizes hepatic lipid metabolism and modulates the gut microbiota; an effect not observed in rats fed a normal diet. The findings of the present study also implicated that the MI ring of PA may be responsible for the beneficial effects of dietary PA on hepatic lipid metabolism and gut microbiota in rats fed an HSC diet. Further studies on the effect of PA or MI intake on lipid metabolism in adipose tissue and mineral metabolism in rats with fatty liver pathology should be performed in order to comprehensively evaluate the properties, bioavailability and safety of PA/MI intake.

\section{Acknowledgements}

Not applicable.

\section{Funding}

The current study was supported by Grants-in-Aid for Scientific Research from the Tojuro Iijima Foundation for Food Science and Technology in Japan (grant no. 15, G-9, 2015).

\section{Availability of data and materials}

The datasets used and/or analyzed during the current study are available from the corresponding author on reasonable request.

\section{Authors' contributions}

YO and TK conceived and designed the experiments. YO and AS performed the experiments and analyzed the data. YO and TK wrote the paper. All authors read and approved the final manuscript.

\section{Ethics approval and consent to participate}

The study was approved by the Ethics Committee of Fuji Women's University (Ishikari, Japan).

\section{Consent for publication}

Not applicable.

\section{Competing interests}

The authors declare that they have no competing interests.

\section{References}

1. Kumar V, Sinha AK, Makkar HPS and Becker K: Dietary roles of phytate and phytase in human nutrition: A review. Food Chem 120: 945-959, 2010.

2. Silva EO and Bracarense AP: Phytic acid: From antinutritional to multiple protection factor of organic systems. J Food Sci 81: R1357-R1362, 2016.

3. Kim JN, Han SN and Kim H-K: Phytic acid and myo-inositol support adipocyte differentiation and improve insulin sensitivity in 3T3-L1 cells. Nutr Res 34: 723-731, 2014.

4. Vucenik I and Shamsuddin AM: Cancer inhibition by inositol hexaphosphate (IP6) and inositol: From laboratory to clinic. J Nutr 133 (Suppl 1): 3778S-3784S, 2003.

5. Katayama T: Effects of dietary myo-inositol or phytic acid on hepatic concentrations of lipids and hepatic activities of lipogenic enzymes in rats fed on corn starch or sucrose. Nutr Res 17: 721-728, 1997.

6. Okazaki Y and Katayama T: Effects of dietary carbohydrate and myo-inositol on metabolic changes in rats fed 1,1,1-trichloro2,2-bis (p-chlorophenyl) ethane (DDT). J Nutr Biochem 14: 81-89, 2003.

7. Okazaki Y and Katayama T: Dietary inositol hexakisphosphate, but not myo-inositol, clearly improves hypercholesterolemia in rats fed casein-type amino acid mixtures and 1,1,1-trichloro-2,2-bis (p-chlorophenyl) ethane. Nutr Res 28: 714-721, 2008.

8. Onomi S, Okazaki Y and Katayama T: Effect of dietary level of phytic acid on hepatic and serum lipid status in rats fed a high-sucrose diet. Biosci Biotechnol Biochem 68: 1379-1381, 2004.

9. Sandberg AS and Andersson H: Effect of dietary phytase on the digestion of phytate in the stomach and small intestine of humans. J Nutr 118: 469-473, 1988.

10. Miyazawa E, Iwabuchi A and Yoshida T: Phytate breakdown and apparent absorption of phosphorus, calcium and magnesium in germfree and conventionalized rats. Nutr Res 16: 603-613, 1996.

11. Okazaki Y and Katayama T: Dietary phytic acid modulates characteristics of the colonic luminal environment and reduces serum levels of proinflammatory cytokines in rats fed a high-fat diet. Nutr Res 34: 1085-1091, 2014.

12. Solga SF and Diehl AM: Non-alcoholic fatty liver disease: Lumenliver interactions and possible role for probiotics. J Hepatol 38: 681-687, 2003.

13. Festi D, Schiumerini R, Eusebi LH, Marasco G, Taddia M and Colecchia A: Gut microbiota and metabolic syndrome. World J Gastroenterol 20: 16079-16094, 2014.

14. Sekita A, Okazaki Y and Katayama T: Dietary phytic acid prevents fatty liver by reducing expression of hepatic lipogenic enzymes and modulates gut microflora in rats fed a high-sucrose diet. Nutrition 32: 720-722, 2016.

15. Hara H, Haga S, Aoyama Y and Kiriyama S: Short-chain fatty acids suppress cholesterol synthesis in rat liver and intestine. J Nutr 129: 942-948, 1999.

16. Kim M and Shin HK: The water-soluble extract of chicory influences serum and liver lipid concentrations, cecal short-chain fatty acid concentrations and fecal lipid excretion in rats. J Nutr 128: 1731-1736, 1998.

17. Reeves PG, Nielsen FH and Fahey GC Jr: AIN-93 purified diets for laboratory rodents: Final report of the American Institute of Nutrition ad hoc writing committee on the reformulation of the AIN-76A rodent diet. J Nutr 123: 1939-1951, 1993. 
18. Croze ML, Géloën A and Soulage CO: Abnormalities in myo-inositol metabolism associated with type 2 diabetes in mice fed a high-fat diet: Benefits of a dietary myo-inositol supplementation. Br J Nutr 113: 1862-1875, 2015.

19. Takahashi Y: Soy protein and fish oil independently decrease serum lipid concentrations but interactively reduce hepatic enzymatic activity and gene expression involved in fatty acid synthesis in rats. J Nutr Sci Vitaminol (Tokyo) 57: 56-64, 2011

20. Yang Y, Sitanggang NV,Kato N, Inoue J, Murakami T, Watanabe T, Iguchi T and Okazaki Y: Beneficial effects of protease preparations derived from Aspergillus on the colonic luminal environment in rats consuming a high-fat diet. Biomed Rep 3: 715-720, 2015.

21. Okazaki Y, Tomotake H, Tsujimoto K, Sasaki M and Kato N: Consumption of a resistant protein, sericin, elevates fecal immunoglobulin A, mucins, and cecal organic acids in rats fed a high-fat diet. J Nutr 141: 1975-1981, 2011.

22. Sakamoto K, Vucenik I and Shamsuddin AM: $\left[{ }^{3} \mathrm{H}\right]$ phytic acid (inositol hexaphosphate) is absorbed and distributed to various tissues in rats. J Nutr 123: 713-720, 1993.

23. Indyk HE, Saldo SC, White PM, Dole MN, Gill BD and Woollard DC: The free and total myo-inositol contents of early lactation and seasonal bovine milk. Int Dairy J 56: 33-37, 2016.

24. Masuda T, Kawano A, Kitahara K, Nagashima K, Aikawa Y and Arai S: Quantitative determination of sugars and myo-inositol in citrus fruits grown in Japan using high-performance anion-exchange chromatography. J Nutr Sci Vitaminol (Tokyo) 49: 64-68, 2003.
25. Xu RY, Wan YP, Fang QY, Lu W and Cai W: Supplementation with probiotics modifies gut flora and attenuates liver fat accumulation in rat nonalcoholic fatty liver disease model. J Clin Biochem Nutr 50: 72-77, 2012.

26. Ritze Y, Bárdos G, Claus A, Ehrmann V, Bergheim I, Schwiertz A and Bischoff SC: Lactobacillus rhamnosus GG protects against non-alcoholic fatty liver disease in mice. PLoS One 9: e80169, 2014.

27. Pagano C, Soardo G, Esposito W, Fallo F, Basan L, Donnini D, Federspil G, Sechi LA and Vettor R: Plasma adiponectin is decreased in nonalcoholic fatty liver disease. Eur J Endocrinol 152: 113-118, 2005.

28. Targher G, Bertolini L, Rodella S, Zoppini G, Scala L, Zenari L and Falezza G: Associations between plasma adiponectin concentrations and liver histology in patients with nonalcoholic fatty liver disease. Clin Endocrinol (Oxf) 64: 679-683, 2006.

29. Xu A, Wang Y, Keshaw H, Xu LY, Lam KSL and Cooper GJS: The fat-derived hormone adiponectin alleviates alcoholic and nonalcoholic fatty liver diseases in mice. J Clin Invest 112: 91-100, 2003. 